\title{
Animals as Social Actors or Objects of Exploitation
}

\author{
Nicholas Miller \\ Ball State University
}

Beginning with the earliest writings of civilization up until the eighteenth century, the focus of the historical narrative has been on the major political contenders, leaders of nations, and catastrophic wars. However, by the beginning of the twentieth century the focus shifted from concentrating on the "movers and shakers of the world" to an inclusion of average people and marginalized groups. According to Daniel Woolf”s A Global History of History, “...the modern 'discipline'... of history has had for about 150 years a very clear set of professional codes and practices, generally understood by most, though of late challenged by alternative practices and differing senses of what is a proper subject for the historian." ${ }^{1}$ No longer is the history of the world solely focused on diplomatic relationships between nations. Instead it is now exceedingly more holistic in how society is viewed, expressed, and developed, with an emphasis on what the general public has to offer to humanity's story. Regardless, to say this approach, which has only affected the quiet voices in history or the underrepresented people in bygone times, is sorely missing the point. This revolutionary shift in historical ideology not only affected the agency of humans in our collective past, but also members of the animal kingdom as well. Animals are represented in artwork, legal proceedings, myths, legends, movies, novels, and even music, and as the historical narrative progresses, the chasm between human and animal is slowly being bridged via literature, metaphor, and changes

\footnotetext{
${ }^{1}$ Daniel Woolf, A Global History of History (Cambridge: Cambridge University Press, 2012), 11.
} 


\section{Miller}

in popular opinion. In addition, while the human-animal relationship is ever present the representation and treatment of animals is continually shifting - this relationship is an organic process filled with dynamic transactions. Nonetheless, this theoretical argument suggests that it is possible to imagine that animals might have a point of view regarding history, and if they do, we should be interpreting that history alongside the other historically underrepresented groups.

The following historiography consists of an examination of animal studies in the discipline of history. When defining this polemical topic, it is important to recognize that the field of animal studies is not based solely within the confines of historical inquiry. Many sources including folkloric beliefs, agricultural motifs, and texts on animal rights advocacy weigh in on the topic of the animal/human binary; however, the interdisciplinary cross section of this field is rife with dissension. This paper will address important issues concerning the increasing denaturalization of the animal/human binary—-the "otherness" of animals in relation to humans-and will support the idea that it is possible to include nonhuman animals in historical accounts. Inclusion of nonhuman subjects in the historical narrative augments our limited — but expandingknowledge of the past. Former portrayals of the dualistic nature of animals and humans will be addressed in this paper, but discussion of these antiquated portrayals will be accompanied by considering other up and coming perspectives regarding nonhuman animals. Theoretical assumptions will rely heavily on postmodern and postcolonial fields of thought with an emphasis on animal rights and the animal-human relationship and its representation within the discipline. 
The hazard with equating this idea of otherness to animals is that it perpetuates the existing divide and naturalization of the animal/human binary. This idea can be associated with Jacques Derrida's emphasis on the notion in his essay In The Animal That Therefore I Am, as he attacks the expression "the animal" as a "catch-all concept" used to "designate every living thing that is held not to be human."2 Perhaps the main issue with allowing an "animal point of view" to history would mean that humanity is realizing that perhaps they are not exceptional and are conceivably just another piece of the biosphere. Key to understanding animals' current place in relation to our own in this shared environment begins with our concept of dominion and hegemony over other species that has been seriously questioned ever since the advent of Darwinian thought. ${ }^{3}$ If human history is reliant upon the natural order, that should require that the history of animals is necessary for our history also. When Darwin published his book On the Origin of Species, he not only opened the floodgates of a controversy regarding the religious paradigm of the time, he also ushered in the possibility that humans are not unique in their mental capacities. More likely than not, we are more similar to other nonhuman animals than we recognize.

Usually when we consider history, we look at records, documents, and more recently oral histories and memoirs. However, when considering a species that does not keep their own records or have written language, there is a question

\footnotetext{
${ }^{2}$ Jacques Derrida, "The Animal That Therefore I Am (More to Follow)," Critical Inquiry 28, no. 2 (2000), 402.

${ }^{3}$ David Gary Shaw, “A Way With Animals,” History and Theory 52, no. 4 (2013): 2, https://www.jstor.org/stable/24542955. The progenitor of this idea is considered Erasmus Darwin, Charles's grandfather.
} 


\section{Miller}

of what could be considered historical documentation. For instance, the humananimal binary is a fascinating topic and has been of interest to humans for millennia. It is not in the scope of this paper to discuss animal depictions throughout the centuries of history, and so for the purpose of brevity and simplicity this paper will focus on broader concepts such as zooarchaeological remains, legal trials, and a few other associated concepts. Looking at these broad categories allows for a more general periphery of nonhuman animal history and avoids specific locus of interest—-such as cats in Egypt or horses from Eurasian steppe civilizations. Furthermore, by avoiding the otherness in human history we can concentrate on the similarities between our species, others and our shared space in the natural environment. One way to concentrate on the analogous relationship of human and animals is to step outside the discipline of history and approach it another way.

In the fundamental text book Zooarchaeology, Elizabeth J Reitz and Elizabeth S. Wing define zooarchaeology as "the study of animal remains excavated from archaeological sites. The goal of zooarchaeology is to understand the relationship between humans and their environment(s), especially between humans and other animal populations." ${ }^{4}$ This mandatory text of most American archaeozoological classrooms expresses that connection between humans and "other" animal populations. Throughout the book Reitz and Wing explain that humans are biologically, ethologically, and ecologically similar to other animals that they research and are examining in the field. Not only that, the field of

\footnotetext{
${ }^{4}$ Elizabeth J. Reitz and Elizabeth S. Wing, Zooarchaeology, 2nd ed. (Cambridge: Cambridge University Press, 2008), 1.
} 
zooarchaeology is multidisciplinary and by virtue of being a branch of anthropology is holistic in its approach-necessary when utilizing faunal remains to discuss cultural history, behavioral adaptations, and social meaning from an assemblage or site. ${ }^{5}$ Zooarchaeology provides one of the many ways to show how inherently flexible human behavior is in relation to their natural and social environment, and how this adaptability is permeable in relationship to their nonhuman relatives. More so than that though, it helps provide a "better understanding of the diverse ways in which humans respond to the challenges and opportunities of their environment; the variety of roles that animals fill; the breath of the animal's social meaning." ${ }^{\prime \prime}$ Through zooarchaeology it is possible to examine ancient faunal remains and reinterpret the role animals and humans alike played in the past. Furthermore, with the advances in archaeogenetics and the analysis of mitochondrial DNA (mtDNA), it is becoming possible to look even further into the animal past. According to Juliet Clutton-Brock, "this has become an increasingly important tool in revealing finer details in the identification of populations of species, the relationship between domestic species and wild progenitors, and the spread of varieties of domestic species from their location of origin." "While it may appear as though zooarchaeology serves as yet another scientific tool that scrutinizes ancient prehistoric human-animal bones and provenance and roles, certain researchers are exploring it further.

\footnotetext{
${ }^{5}$ Reitz and Wing, Zooarchaeology, 29.

${ }^{6}$ Ibid., 335.

${ }^{7}$ Juliet Clutton-Brock, "Archaeozoology," in The Oxford Handbook of Animal Studies, ed. Linda Kalof, 1st ed. (Oxford: Oxford University Press, 2017), 477.
} 
In Nerissa Russell's captivating book Social Zooarchaeology: Humans and Animals in Prehistory, the author explores what it means to be an "animal". According to Russell, "the opposition of humans and animals is artificial and anthropocentric. Humans are one animal species among many; like all other species we are by definition unique, but we do not logically form a category opposed to (and above) all other species." 8 Russell understands the uniqueness of all animals and that we all have a part to play in history. The book argues that animals have contributed more to human history than just fodder for the human diet and roles in subsistence economies Russell explores the relationship of human and animals with the latter's continued duty as companions, spiritual helpers, sacrificial victims, totems, objects of taboo, and more. What makes this argument so intriguing is the fact that, although this book utilizes zooarchaeology and faunal analysis, it also incorporates evidence from ethnographies, history, and classical studies. Furthermore, Russell tackles the concepts of anthropocentrism and anthropomorphism and explains them as, "anthropocentrism inscribes a sharp human-animal boundary and privileges humans strongly, whereas anthropomorphism erases the boundary and risks denying animals their own unique identities." 9 These two notions attack the sensibility of the scientific community — "the attribution of any 'human' qualities to animals...was seen as unwarranted projection"- - but are nonetheless crucial in grasping the breach in the human-animal boundary by applying the ethical

\footnotetext{
${ }^{8}$ Nerissa Russel, Social Zooarchaeology: Humans and Animals in Prehistory (Cambridge: Cambridge University Press, 2012), 2.

${ }^{9}$ Russell, Social Zooarchaeology, 2.
} 
system we apply to humans to other species, as well as the agency and choice we commonly assume to be human attributes. ${ }^{10}$

The discourse on the origins of animal domestication tends to focus on "the issue of intentionality" — the degree to which domestication was the product of deliberate human choice. ${ }^{11}$ Whether this choice was deliberate or not, the domestication of plants and animals marked a major evolutionary transition in human history. Emma R. Power states, "Domestication is a key process through which humans have claimed dominance over nature, including nonhuman natures and the nature of the human body. It has most often been examined as an historic biological and cultural process through which the 'wildness' of plants and animals was brought in and re-made in the image of human culture through selective breeding and incorporation into human social structure." 12 Contrary to this idea, the introduction of canines into the history of humanity has raised arguments for the concept of "mutual domestication" - the notion that while we were domesticating dogs, they were in turn domesticating us. With the dog being regarded as humanity's first domesticated animal-evidence for the domestication of the dog reaches as far back as the Neolithic_-was this taming actually "self-domestication," the colonization of new ecological niches by animals such as wolves? Or did it result from intentional decisions of human

\footnotetext{
${ }^{10}$ Russell, Social Zooarchaeology, 2.

${ }^{11}$ Lyudmila N. Trut, "Early Canid Domestication: The Farm-Fox Experiment: Foxes bred for tamability in a 40-year experiment exhibit remarkable transformations that suggest an interplay between behavioral genetics and development," American Scientist 87, no. 2 (1999): 160.

${ }^{12}$ Emma R. Power, "Domestication and the Dog: Embodying Home," Area 44, no. 3 (2012): 371 .
} 


\section{Miller}

beings? ${ }^{13}$ Regardless of the origins of this companionship, domestic animals have become intricately woven into human economy, society, and religion. ${ }^{14} \mathrm{Per}$ Melinda Zeder, "animal domestication is an on-going process, as humans, with increasingly sophisticated technology for breeding and rearing animals in captivity, continue to bring more and more species under their control."15 Nevertheless, ideas such as "mutual-domestication" have led the discourse on a shared collaboration of humans and animals and strongly suggest an intertwined history.

During the Middle Ages and Renaissance, animals were placed in parallel — with regard to their moral and conscientious behavior-to their owners. Even though a creature was considered to be the property of its master, it was held to the same level of sentience as a human. For example, the thirteenth century provides the first recorded legal trial of a nonhuman mammal committing murder. ${ }^{16}$ By definition, murder is the premeditated killing of another human being. Following this rationale, in order to be capable of committing murder, the animal had to have contemplated its actions and then made a deliberate choice to kill. In the aforementioned thirteenth century trial, a pig was accused of killing a child and then eating it - the sentence was burning in the public square. ${ }^{17}$ Interestingly, the pig was most likely someone's property, but the verdict was

\footnotetext{
${ }^{13}$ Lyudmila N. Trut, "Early Canid Domestication," 160.

${ }^{14}$ Melinda A. Zeder, "The Domestication of Animals," Journal of Anthropological Research 68, no. 2 (2012): 161.

${ }^{15}$ Zeder, "The Domestication of Animals," 161.

${ }^{16}$ Joyce Salisbury, The Beast Within: Animals in the Middle Ages, 2nd ed. (Abingdon: Routledge, 2010), 108.

${ }^{17}$ Salisbury, The Beast Within, 108.
} 
carried out as though the animal were a human with free will to chose to kill and eat the child. Clearly, in this case, people in authority applied profoundly human qualities to a nonhuman animal. This begs the question of whether or not other animals were likewise granted agency within the human world.

A second, even more interesting case presented itself a century later in 1386, when another pig was accused of murder by means of tearing the face and arms off a child. ${ }^{18}$ In this case, however, the sow's punishment was to be maimed in the same manner as the child. The pig was then dressed like a man and paraded through the city before being executed. This incident is even more thoughtprovoking than the first, not only due to the fact that the pig was clad like a human, but also because throughout the rest of the trial and execution the pig was treated like a human defendant. For instance, the executioner was paid the same fee that he would have received for executing a human. In addition, the state furnished the man with a new pair of gloves, "so his hands were 'clean' of the guilt of shedding blood." 19 It begs the question, why would an executioner feel guilty for killing a pig — an animal that would have been consumed without a second thought? Also, why would anyone pay to have an executioner perform the killing of the pig instead of handing the delinquent animal over to a butcher? Much like the previous case, it appears as though the pig was considered the master of its own will, deserving of treatment equal to that of humans.

\footnotetext{
${ }^{18}$ Salisbury, The Beast Within, 108.

${ }^{19}$ Ibid.
} 
In 1457 , one final pig was put on trial along with her six piglets for the same capital offense as the two previously mentioned cases. ${ }^{20}$ This final situation is unique in that there are records of a month-long imprisonment for all seven of these pigs, along with surviving records giving accounts of the trial and other legal proceedings. During the investigation and sentencing process, a judge, a lawyer, two prosecutors, eight named witnesses, and numerous other unnamed witnesses took part in the trial. ${ }^{21}$ According to Esther Cohen,

though the owner was formally the defendant, it is clear from the proceedings that he stood accused only of negligence and was in no danger of any personal punishment. Moreover, he was allowed to argue in court "concerning the punishment and just execution that should be inflicted upon the said sow", if he could give any reason why the sow should be spared. The owner having waived this right, the prosecutor requested a death sentence. ${ }^{22}$

Eventually the sow would be hanged, and according to the local authorities on the matter, upside down. But what about the piglets? Since there was no proof of them participating in the murder, they were free to go back to the custody of their owner on the condition that he vouch for their future behavior. The master, however, acknowledged that he could not control the free will of the pigs and he declined to take responsibility of the piglets, who "were declared forfeit to the local lord's justice, though they suffered no further punishment." ${ }^{23}$ The owner accepted that he could not govern the desires of his property and grudgingly acquiesced to the ruling of the magistrate.

\footnotetext{
${ }^{20}$ Esther Cohen, “Law, Folklore and Animal Lore,” Past \& Present, no. 110 (1986): 10, https://www.jstor.org/stable/650647.

${ }^{21}$ Cohen, "Law, Folklore and Animal Lore," 10.

${ }^{22}$ Ibid., 11.

${ }^{23}$ Ibid.
} 
All of the pigs above were accused of committing the most heinous deed that any human being could commit and were treated as any human would have been treated. These trial proceedings represent the human desire to understand the action of animals within the purview of their own worldviews. What makes it possible for us to treat animals as akin to ourselves but yet underrepresent them throughout history? Humans arbitrarily judge nonhuman animals according to their convenience, but historians still struggle with placing them into the human narrative outside of treatises acknowledging their agricultural and economic importance. Despite widespread shortcomings, there are a few documented cases of human-animal transactions that extend beyond the material and productive aspect of this relationship. In fact, some animals have been elevated to a higher status than their historical human compatriots.

Roughly the same time and location-France —of the first recorded nonhuman murderer, a legend involving a dog, begins to develop in thirteenth century Europe. Although there are multiple legends involving wrongfully accused and murdered animals, in The Holy Greyhound: Guinefort, Healer of Children Since the Thirteenth Century Jean-Claude Schmidt specifically investigates the cult of "Saint Guinefort" and explains how this dog rose from being unjustly murdered to his evolution into a saint. ${ }^{24}$ Once a lowly canineeven though the Greyhound was considered the noblest of breeds - the dog

\footnotetext{
24 Jean-Claude Schmidtt, The Holy Greyhound: Guinefort, Healer of Children Since the Thirteenth Century, Cambridge Studies in Oral and Literate Cultures (Cambridge: Cambridge University Press, 1979), 63. The chapter, The Legend, splits the narrative and analyzes it piece by piece, so a definitive page number is hard to express. I established this page simply because it is discussing his burial and the concept of the gates of Hell.
} 


\section{Miller}

became a symbol of healing and the peasants would bring their sick children to his grave to preserve them from disease and to keep the plague at bay. ${ }^{25}$ While the previous animal cases in this paper concerned the secular sphere, Schmidt brings the animal to the religious realm and broadens the human-animal relationship discourse by placing St. Guinefort in a place of spiritual importance. Although this animal and cult of peasants represented the divine status of animals, it also provides the historian an access point into their secular history and what was important to their everyday existence. By exploring this martyred animal's background and life, historians and anthropologists can catch a glimpse of local traditions and practices of peasant life of thirteenth century Dombes. Schmidt's analysis provides the necessary means to engage the past by using an animal as a focal point and allows for an expansion of the narrative beyond the animal to include information about the peasants who paid him homage. From these few examples it appears that death has been key to answering the role animals play in defining our definitions of good and evil, either through the martyrdom of a holy greyhound or the execution of convicted animal murderers. Conversely, the preemptive killing of these creatures by humans does not automatically necessitate their role in our society or their place in history. For that we must look deeper into the subject at hand and try to find what does dictate the nonhuman animals' role in all of this.

The simplest way to achieve a fuller understanding of the discourse regarding human-animal relationships is to look at the major questions and

\footnotetext{
${ }^{25}$ Schmidtt, The Holy Greyhound, 93.
} 
methods currently being produced in the discourse. A central argument is whether or not it is important or worthwhile to emphasize the contributions of animals in history. Other voices in the argument ask if it is even possible to separate animals from human history. According to Martha Few and Zeb Tortorici in their Introduction to Centering Animals in Latin American History, the study of animals in history has produced the question "does the centering of animals - the transforming of nonhuman animals into central actors in the historical narrative - provide us with significantly different versions of the past than those historical works that solely present animals as visible and important factors in history?"26 Although documentation of agricultural and economic records concerning animals have been a constant since the advent of writing, could animals provide more than just an account of how we have exploited them throughout the ages and be the key to a richer history in general?

The problem with studying marginalized history and exploitation is that it shifts the discipline from purely academic into a quagmire of moral and philosophical questioning and more often than not a political debate. Not only must these marginalized populations shake off the history of disparagement and indoctrinated interpretations, but also the people who study the history of the marginalized must continuously justify the inclusion of these histories in the first place. Furthermore, some academics and indigenous people question who should be allowed to study marginalized groups, stating that the average historian may

\footnotetext{
${ }^{26}$ Martha Few and Zeb Tortorici, eds., Centering Animals in Latin American History (Durham: Duke University Press, 2013), 3.
} 


\section{Miller}

not have the necessary tools to advocate for these subsets, thereby making an emic position an indispensable qualification for perpetuating the history of certain groups. In theory, this issue could be addressed and when it comes to discussing the history of humans and their place in the world, cultural and grassroots histories have certainly entertained and explored this phenomenal idea. However, resolving difficulties associated with this theoretical standpoint becomes much more problematic when the discourse revolves around nonhuman animals. Methodological documents about animals are created for humans, by humans. ${ }^{27}$ Humans evince their authority and dominion over animals by prescribing cultural significance, political and moral symbolism to each animal. What with this being the case, how does the historian include nonhuman animals as another social actor (alongside social classes, women, the state, the church, etc.) in the histories they write? ${ }^{28}$ These questions present an interesting conundrum that may create obstacles to including animals in the wider realm of historical narratives and ethnographical studies.

According to David Shaw, these issues and questions could not have been addressed until recently by historians. ${ }^{29}$ When humanity considers its past, it looks at its ancestors to remember achievements and reflect on what we have learned from them. This shortsighted statement has its limitations though and does not aptly apply to the role that animals have played in humanity's

\footnotetext{
${ }^{27}$ Few and Tortorici, Centering Animals, 3.

${ }^{28}$ Ibid.

${ }^{29}$ David Gary Shaw, “A Way With Animals,” History and Theory 52, no. 4 (2013): 1, https://www.jstor.org/stable/24542955.
} 
progression. In $A$ Way with Animals, Shaw argues "that 'we' was always a way of saying 'those enough like us to count.' The 'we' sets limits. It's our gang, a social group, whether a king and his crony vassals, the senate and people of Rome, the subjects of the Middle Kingdom, or all humanity." ${ }^{30}$ The expression of this idea allows for a theoretical approach that not only splits the history of humanity into multiple narratives-possibly a different history for each represented group — but also allows for the possibility of other and more distinct historical points of view to be addressed.

At this point in time, we are becoming uniquely equipped to handle and understand important contemporary topics, including precarious subjects such as racism and sexism, and the underrepresented and misrepresented groups associated with them. Although we are a long way away from fully grasping and deciphering the history of these neglected groups, the development of that process is being attempted, and we are becoming increasingly aware of disenfranchisement in the discipline. This development is a work in progress, and it follows that there have been mistakes made and probably many more to come. One of these mistakes includes the idea of essentialism - "assuming that things or structures have one set of characteristics which is basic, or in a cognate sense 'foundational"' - and it affects the discipline regarding these unheard groups. ${ }^{31}$ Groups that have their own voice can propose their own interests and can advocate for what best represents them - they do not need a researcher telling

\footnotetext{
${ }^{30}$ Shaw, "A Way With Animals," 1.

${ }^{31}$ Anna Green and Kathleen Troup, The Houses of History a Critical Reader in History and Theory (Manchester: Manchester University Press, 1999), 297.
} 


\section{Miller}

them what it is best. However, historians are also tasked with representing the groups that cannot speak for themselves. Much like David Shaw, Kari Weil is a proponent of animal rights and the need for their story to be heard. Her work, $A$ Report on the Animal Turn, centers around a concept made famous by Peter Singer — speciesism—and emphasizes this discrimination went largely unnoticed both inside and outside academia. ${ }^{32}$ Much like racism and sexism, Weil thinks it is time that animal rights be addressed in the scholarly world in order to dissolve the gap between human and animals in the discourse.

According to Weil, "for centuries nonhuman animals have been locked in representations authored by humans, representations that, moreover, have justified their use and abuse by humans." ${ }^{33}$ She begins this position by stating that a similar argument has been used to justify "Women's studies and ethnic studies programs in their demands that the academy acknowledge and address the underrepresentation and misrepresentation of groups of people under the forces of sexism and racism." 34 This is a noble and justified pursuit and should be addressed, however, while the women and minorities lacking representation can write and voice their issues and concerns, how do animals pursue the same course of action? The objective of this reasoning is not to suggest that animals can be or want to be heard, but rather that the discourse should attract attention to them as a marginalized group and their limited status as objects instead of

\footnotetext{
${ }^{32}$ Kari Weil, "A Report on the Animal Turn," in Thinking Animals: Why Animal Studies Now? (New York City: Columbia University Press, 2012), 2.

${ }^{33}$ Weil, "A Report on the Animal Turn," 2.

${ }^{34}$ Ibid., 1.
} 
representative agents. ${ }^{35}$ If other groups are finally being represented then so should animals. As Weil states, "if animal studies have come of age, it is perhaps because nonhuman animals have become a limit case for theories of difference, otherness, and power. ${ }^{{ }^{36}}$ However, this perpetuates the notion that the status of otherness is cause for representation.

In Hunters, Herders, and Hamburgers: The Past and Future of HumanAnimal Relationships, Richard W. Bulliet describes the inconsistent relationship between humans and animals. Bulliet elaborates on four stages of history of this relationship — separation, predomesticity, domesticity, and postdomesticity. Bulliet mainly focuses on America, and explains that the contemporary state of postdomesticity allows humanity to distance itself, "both physically and psychologically, from the animals that produce the food, fiber, and hides they depend on...Yet they maintain very close relationships with companion animals - pets—often relating to them as if they were human." ${ }^{37}$ The book explores our current era of postdomesticity and argues that although humans remain dependent on animal products, they do not have any desire, ethically or otherwise, to have any involvement with the processing and production of these items. The social and technological developments of developed nations have divided the animal side of the animal-human relationship into either companion animals or other, where the other is disregarded and not considered. According

\footnotetext{
${ }^{35}$ Ibid.

${ }^{36}$ Ibid., 3.

${ }^{37}$ Richard W. Bulliet, Hunters, Herders, and Hamburgers: The Past and Future of Human-Animal Relationships (New York City: Columbia University Press, 2007), 3.
} 


\section{Miller}

to Margo DeMello, "one of the most important criteria for being a pet is having a name because having a name symbolically and literally incorporates that animal in the human domestic sphere." ${ }^{38}$ This allows communication with the animal — understood or not—and develops a social contract that builds a relationship with the animal. However, the modern public opinion regarding companion animals must dictate a reconciliation between humans and nonhuman animals and suggest a different kind of relationship is forming. One such example of this reconciliation happened in the twentieth century and its source is quite shocking.

In Nazi Germany, some of the most stringent animal welfare laws were developed and carried substantial punishments for any violations. In Animals in the Third Reich, Boria Sax expresses the complex ways that animals can be used for politics and how they can help shape human culture through myths and symbols. Furthermore, he explores the legal system and the laws that were implemented during this crisis in world history. Just like "St. Guinefort," in Nazi Germany the animal was raised above certain individuals-Jews. While the Germans were allowed to persecute, murder, and torture Jews, animals held a unique status in Germany and were treated much more humanely than fellow humans. According to Sax, "a new protection law was being formulated which would bring 'unity' to domestic life...the introduction to the law stated clearly that animals were not to be protected for the sake of human beings but 'for their

\footnotetext{
${ }^{38}$ Margo DeMello, Animals and Society: An Introduction to Human-Animal Studies (New York City: Columbia University Press, 2012), 156.
} 
own sakes." ${ }^{39}$ However, unlike Peter Singer's utilitarian theory- "based on the principle of equal consideration, which means that we must give equal consideration to the interests of all creatures, and we should maximize the satisfaction of the interests of everyone...who are affected by our actions"Nazism pushed the human animal relationship to a new level. ${ }^{40}$ Sax suggests that Nazi Germany blurred the boundary between human and animals, and this "enabled the regime to breed, herd, and slaughter people like livestock." ${ }^{11}$ This statement presents the argument whether or not we should breakdown the divisions between humans and animals, for it could jeopardize our ideals of human rights. ${ }^{42}$ If that is the case, how should we represent animals in history? Do they hold a special position that we cannot touch yet, or do we treat them like separate entities that we discuss gingerly?

Tok Thompson argues that nonhuman animals have their own culture and folklore, and "since folklore is a discipline focusing on the very topic of collectively shaped, traditional, expressive culture, it would seem to be in an ideal position to take the lead in this newly emerging realm of the study of culture beyond the human." 43 Thompson wants to breakdown the human-animal binary

\footnotetext{
${ }^{39}$ Boria Sax, Animals in the Third Reich, Second (Providence: Yogh \& Thorn Press, 2013), 101.

${ }^{40}$ DeMello, Animals and Society, 386.

${ }^{41}$ Boria Sax, "The Cosmic Spider and Her Worldwide Web: Sacred and Symbolic Animals in the Era of Change," in A Cultural History of Animals in the Modern Age, ed. Randy Malamud (Oxford \& New York: Berg Publisher, 2007), 45.

${ }^{42}$ Sax, "The Cosmic Spider," 45.

${ }^{43}$ Tok Thompson, "Folklore beyond the Human: Toward a Trans-Special Understanding of Culture, Communication, and Aesthetics," Journal of Folklore Research 55, no. 2 (2018): 69, https://doi.org/10.2979/jfolkrese.55.2.04.
} 


\section{Miller}

and open-up ways that scholarship can engage with animal thoughts, not just the thoughts that humans have of animals. ${ }^{44}$ The author provides multiple examples of "the study of nonhuman expressive culture in a philosophical framework," including songbirds that change their song and style over time, demonstrations of nonhuman language and dialect, and even naming within species. ${ }^{45}$ What Thompson suggests is that humans need to change their understanding of culture and how it works. It "should be rethought, restudied, and reevaluated on a scale much grander and larger than anything we have considered before." ${ }^{46} \mathrm{He}$ advances the idea that traditions and cultures are much larger than the human condition, and acknowledging this and investigating it is the "necessary step for the future of folklore studies, and for the future of scholarly understanding of

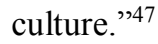

Interpretation of the theoretical framework of animal studies in historical study has appeared to be arguably split between animal rights advocates, historians, folklorists, and scientists. However, the shifting of the historiography that appeared in this paper represents only a fraction of information that could have been drawn upon. Animals have always been a fascinating object of study, to the naturalist or the historian, but now they are becoming objects of representation $-\mathrm{a}$ fact that scholars need to address. Speciesism is becoming a topic of political debate and philosophical questioning nearly equal to the topics of racism and sexism. Furthermore, animals' position

\footnotetext{
${ }^{44}$ Tok Thompson, "Folklore beyond the Human," 70.

${ }^{45}$ Tok Thompson, "Folklore beyond the Human," 71.

${ }^{46}$ Ibid., 85.

${ }^{47}$ Ibid.
} 
in legal systems have shifted from capital punishment in the late Middle Ages and Renaissance to animals having more rights than other marginalized groups during Nazi extremism. With this rise in contractual—legally or sociallyrelationships with animals, mankind is distancing itself from other creatures while simultaneously blurring the boundaries between our animal-human binary. In post-domesticity humans often ignore the animals used for food and clothing but treat pets as humans and equals. The problem this causes for historians is certainly unavoidable, but to associate with these varying polemical constructs allows them to instead turn to contemporary issues. Tok Thompson argues that nonhuman animals have their own version of a quiet voice, a sound that gives substance to the silence often prescribed them. His idea of nonhuman animal culture and folklore may finally give animals a voice in generating their own perspective in relation to the environment and the history of the planet. Nonhuman animal folklore may allow the historian to conceptualize neglected aspects of the discourse and add to the ever growing and ever-changing idea of what comprises the animal-human binary, if it exists at all. 